Научная статья

УДК 141

DOI: 10.18101/1994-0866-2021-4-70-75

\title{
СОЦИАЛЬНЫЙ КОНФЛИКТ С ПОЗИЦИЙ СИНЕРГЕТИЧЕСКОГО ПОДХОДА: СОЦИАЛЬНО-ФИЛОСОФСКИЙ АНАЛИЗ
}

\author{
(C) Жапова Наталья Амогалановна \\ кандидат философских наук, старший преподаватель, \\ Бурятский государственный университет имени Доржи Банзарова \\ Россия, 670000, г. Улан-Удэ, ул. Смолина, 24 а \\ tumann479@mail.ru
}

\begin{abstract}
Аннотация. Статья посвящена социально-философскому анализу конфликта в рамках синергетической парадигмы. Автор полагает, что в изучении социальных конфликтов наиболее эффективным подходом является теория самоорганизации, которая реализуется в рамках системно-синергетического подхода. В силу своего междисциплинарного характера и универсальности законов и принципов синергетический подход обладает большим исследовательским потенциалом при изучении общественных процессов. Можно предположить, что синергетика позволит привнести новое в конфликтологическое знание, станет его мировоззренческим базисом. Современная наука уже не ориентируется на идеалы неизменности и линейности, поэтому и в изучении конфликтов также нужно искать факторы самоорганизации, ветви стратегий и бифуркации как пути выхода из кризисных состояний. Автор приходит к выводу, что нужно учитывать постоянство самого феномена конфликтности в социальном пространстве, функциональную нагрузку конфликтов и органическую связь конфликтов с изменениями в общественном развитии.

Ключевые слова: синергетика, системный подход, социальный конфликт, теория самоорганизации, социальная система, общество, конфликтология, общественная трансформация, глобализация, социальные процессы.
\end{abstract}

\section{Для цитирования}

Жапова Н. А. Социальный конфликт с позиций синергетического подхода: социально-философский анализ // Вестник Бурятского государственного университета. Философия. 2021. Вып. 4. С. 70-75.

На сегодня стоит задача развития философской теории конфликта. Данная тема, несомненно, является актуальной для современной российской действительности. Реалии нашей жизни показывают рост социальных конфликтов, их остроту и динамичность. К сожалению, экономические, политические, культурные факторы сегодня не являются чем-то сдерживающим социальную напряженность. Напротив, мы видим тенденцию роста конфликтогенности в самых разных областях социума.

Как нам представляется, в изучении социальных конфликтов имеется большая эвристическая возможность у синергетического подхода. Если ранее конфликты изучались больше как отдельные локальные явления, то сегодня на конфликт целесообразнее смотреть как на системообразующий фактор развития общества. Системно-синергетическая парадигма обладает междисциплинарным характером и универсальностью законов и принципов, она направлена на диалог 
H. A. Жапова. Социальный конфликт с позиций синергетического подхода: социальнофилософский анализ

социогуманитарных и естественнонаучных знаний. Это дает ей большой исследовательский потенциал при изучении социальных процессов. Так, по мнению В. В. Васильковой, «она является попыткой рационально объяснить не рационально устроенный мир, или точнее, пытается создать рациональную модель нерационально устроенного мира» [4]. Методологическое использование таких понятий, как неравновесность, неустойчивость, стохастичность, хаос, организация и самоорганизация, позволяет конкретизировать источники и факторы социальных конфликтов, их роль в развитии общества, а также позволяет найти пути их регулирования и разрешения. Отметим, что теория самоорганизации смотрит на общество как на открытую, нелинейно эволюционирующую систему, находящуюся в состоянии неравновесности.

Актуальность изучения социальных конфликтов связана с тем положением, в котором оказалось современное российское общество. Это и утрата идеологии, и смена ценностных ориентиров, и перемена форм собственности, и новые трудовые отношения. Новым фактором, обострившим сегодня социальные конфликты, явилась и пандемия новой коронавирусной инфекции.

Рассмотрению социальных конфликтов посвящено немало трудов мыслителей разных эпох, школ и направлений. Так как войны, революции, социальные противоречия всегда давали пищу для размышлений, пытливые умы пытались найти причины их проявления. В общественно-политической мысли таких философов, как Платон, Аристотель, Т. Гоббс, Н. Макиавелли, И. Кант, Г. Гегель, уже можно найти глубокие мысли о природе социального конфликта. Однако, как отмечают исследователи, появление теории конфликта связано с именами К. Маркса, Г. Зиммеля, Э. Дюркгейма, М. Вебера. Так, в марксизме конфликт рассматривался как свойственный именно классовому обществу, в котором существует неравный доступ к ресурсам. Социал-дарвинизм рассматривал социальный конфликт как естественную форму отношений, характерную для всех биологических видов, т. е. как борьбу за выживание. С позиций функционализма социальный конфликт изучался как выполняющий позитивные функции в обществе либо как негативное аномальное явление.

В отечественной науке исследователи также обращались к проблемам конфликтов. Так, в 20-е гг. XX в. это было изучение забастовок, мятежей, стачек, характерных для этого периода истории. Затем, начиная со 2-й половины XX в., начались исследования конфликтов в трудовых коллективах. Нужно отметить, что в советское время конфликты изучались с позиции коммунистической идеологии, т. е. постулировалось, что в социалистическом обществе для конфликтов не останется места, так как исчезнут классовые противоречия - главный источник социальных конфликтов. С начала 90-х годов XX в. отечественная теория конфликта получила новый импульс развития. В результате исследований появились монографии, посвященные самому понятию «конфликт», терминологическим основаниям конфликтологии, а также по методам управления и регулирования конфликтов (А. Я. Анцупов, С. Л. Прошанов [1], А. Г. Здравомыслов [7], А. С. Ахиезер [3], Е. Н. Степанов [10] и др.). Также увеличивается количество исследований, в которых обосновывается применение синергетического подхода при рассмотрении конфликтного взаимодействия в обществе $[5,9]$. Это позволи- 
ло взглянуть на социальный конфликт как на своеобразный способ самоорганизации жизни общества.

Социальный конфликт является атрибутом общественной жизни. Конфликты существуют во всех сферах социальной системы - от макроуровня до микроуровня. Но именно в переходный период, когда состояние социума характеризуется неравновесностью и неустойчивостью, конфликтогенность повышается. Это мы наблюдаем сейчас в современной России. Происходящий период трансформации российского общества характеризуется многими противоречиями, чему способствует ухудшение социально-экономического положения людей, социальное расслоение по уровням доходов, рост безработицы, криминализация и маргинализация. Переходный период накладывает свой отпечаток не только на количество конфликтов, но и на их качество. Трансформационные процессы отвечают за остроту и глубину социальных конфликтов, определяют их подчас деструктивный характер и чаще привлекают силовое решение конфликтов.

Классик западной конфликтологии Льюис Козер отмечал, что конфликты могут являться источником социальных изменения, социального развития [8]. Немецкий конфликтолог Р. Дарендорф также рассматривает конфликт как источник изменений и развития общества. По мнению немецкого ученого, социальные противоречия нельзя устранить из жизни общества [6, с. 93]. Системный подход позволяет предположить, что конфликт является закономерным явлением общественной жизни. Более того, сам рост конфликтов является следствием нелинейности современного мира. А увеличение конфликтов и разного рода кризисов заставляет современного человека жить в постоянной нестабильности и неустойчивости. Поэтому сегодня очень важно развивать человеку активность и нелинейное мышление, быстро реагировать на изменения во внешней среде, ориентироваться в потоках информации, находить выход из любой конфликтной ситуации.

Возможно, именно синергетическая парадигма конфликтологического знания соответствует современному мироустройству, так как представляет мир самоорганизующимся и единым в его целостности. Можно предположить, что синергетический подход позволит привнести новое в конфликтологическое знание, станет его мировоззренческим базисом. Современная наука уже не ориентируется на идеалы неизменности и линейности, поэтому и в изучении конфликтов также нужно искать факторы самоорганизации, ветви стратегий и бифуркации как пути выхода из кризисных состояний.

Конфликтный процесс, в свою очередь, также подчинен принципу самоорганизации и обусловлен единством и целостностью мира. В жизни открытого общества всегда возникают конфликтные ситуации. Но с позиции синергетики социальные конфликты можно рассматривать как регулятор общественного развития, помогающий системе переходить от данных форм развития к более прогрессивным. Однако при этом стоит задача максимально обращать конфликтные ситуации в позитивный фактор, способствующий конструктивному созиданию нового. Исследователи сегодня отмечают, что социальная стабильность зависит от динамичности общественного развития. Если раньше существовала зависимость между стабильностью и застоем и стагнацией, то сегодня в условиях глобализации такого уже нет. Напротив, чем общество более динамично развивается, тем 
H. A. Жапова. Социальный конфликт с позиций синергетического подхода: социальнофилософский анализ

более оно стабильно. Следовательно, конфликты могут стать источником общественных изменений, акцентируя наше внимание на многовариантности и нелинейности развития общества. Поэтому позитивный потенциал конфликтов обязательно следует включать в рассмотрение процессов самоорганизации и саморегулирования общества. Конфликты предопределяют динамизм социальных преобразований. Являясь особым типом социального взаимодействия, они имманентно присущи процессу трансформации общества, входят в социальные процессы и тем самым являются фактором социальной динамики.

Конфликт является точкой актуализации социальных противоречий, в которой аккумулируется энергия социальных субъектов, порождающая сдвиги и социальные изменения. И нужно всегда помнить, что нельзя силой подавлять эти конфликты. Это может повлечь деструктивные свойства конфликта и вызвать взрыв социальной системы. Метод подавления социальных конфликтов является неэффективным способом регулирования. Напротив, нужно способствовать выявлению конструктивного потенциала социального конфликта, возможно, даже путем длительного сосуществования конфликтных групп и противоречий.

В XXI в., в эпоху глобализации, конфликт становится этапом развития общества. Сегодня растет взаимосвязь и взаимозависимость стран и регионов, что отражает процессы мировой глобализации. Данные процессы проявляются в разных областях жизни, в том числе и в конфликтном взаимодействии. Конфликт выступает как системообразующий фактор общественных отношений в различных сферах жизни общества: и в политике, и в экономике, и в технологии. Тем самым формируется новый глобальный мир, в котором конфликт становится точкой бифуркации, определяющей контуры новой глобальной цивилизации. Поэтому социальные конфликты как самоорганизующаяся модель социальной действительности играют большую роль в обеспечении динамического развития системы общества. В эпоху глобализации конфликт становится закономерным этапом в развитии общества, так как представляет собой противоборство сил, итогом которого становится модернизация устоявшегося миропорядка.

Конфликтное взаимодействие является нелинейным процессом. Поэтому при его изучении требуется применять нелинейные подходы, учитывающие степень конструктивности или деструктивности того или иного конфликта. Здесь важным становится не ликвидация, а управление социальным конфликтом, придание ему той формы, которая позволила бы оптимизировать дальнейшее социальное развитие.

Синергетика, изучая механизмы самоорганизации в открытых системах, отмечает целостность мира. И рассматривая развитие социальных систем, синергетический подход выделяет конфликт как важный элемент этого процесса развития. Кроме того, синергетика позволяет взглянуть на конфликт как на технологию управления общественным развитием. Социальный конфликт - это явление, которое протекает внутри системы, он отражает форму взаимодействия структурных элементов системы и влияет на ее развитие. Когда социальная система стабильная, социальные конфликты протекают на микроуровне как межличностные противоречия. Пока система устойчива, она сама гасит подобные внутренние противоречия. Когда же социальная система начинает терять устойчивость под воздействием внешних и внутренних факторов, социальные конфликты с 
микроуровня переходят на макроуровень. На этом этапе возможно перестраивание социальной системы, нахождение новых форм социальной структуры. Изменяются основные центры системы, меняются свойства системы, меняются цели и задачи эволюции и в конечном итоге система выходит на новый путь развития. Получается, что с помощью конфликта система приспосабливается к новым изменившимися условиям и находит новое направление для своего развития. Социальный конфликт и на микроуровне, и на макроуровне является фактором самоорганизации социальных систем. И учитывая это, можно максимально безболезненно переводить энергию конфликтов в позитивное русло.

На наш взгляд, важным является более широкое теоретико-методологическое обоснование социального конфликта, нежели его определение просто как борьба или столкновение противоположных сторон. Нужно учитывать постоянство самого феномена конфликтности в социальном пространстве, функциональную нагрузку конфликтов и органическую связь конфликтов с изменениями в общественном развитии. Синергетика и системный подход дают такое широкое понимание конфликта, указывая на структурно-функциональную связь с социальной действительностью. Применение синергетической парадигмы позволяет поновому взглянуть на природу социального конфликта, а также понять причины и многовариантность исторического развития общества.

\section{Литература}

1. Анцупов А. Я., Прошанов, С. Л. Конфликтология: междисциплинарный подход. Обзор диссертационных исследований. Москва: Дом Советов, 1997. 240 с. Текст: непосредственный.

2. Аршинов В. И., Свирский, Я. И. Философия самоорганизации. Новые горизонты // Общественные науки и современность. 1993. № 3. С. 59-70. Текст: непосредственный.

3. Ахиезер А. С. Жизнеспособность российского общества // Общественные науки и современность. 1996. № 6. С. 58-66. Текст: непосредственный.

4. Василькова В. В. Порядок и хаос в развитии социальных систем: (синергетика и теория социальной самоорганизации). Санкт-Петербург: Лань, 1999. 480 с. Текст: непосредственный.

5. Волновые процессы в общественном развитии / под редакцией В. В. Васильковой, И. П. Яковлева, И. Н. Барыгина и др. Новосибирск: Изд-во Новосибирского университета, 1992. 228 с. Текст: непосредственный.

6. Дарендорф Р. Современный социальный конфликт: эссе о политике свободы // Социальный конфликт: современные исследования. Реферативный сборник. Москва: ИНИ ОН АН СССР, 1991. 114 с. Текст: непосредственный.

7. 3 дравомыслов А. Г. Социология конфликта: Россия на путях преодоления кризиса. Москва: Аспект Пресс, 1994. 317 с. Текст: непосредственный.

8. Козер JI. Функции социального конфликта. Москва: Идея-Пресс, Дом интеллектуальной книги, 2000. 208 с. Текст: непосредственный.

9. Социальные конфликты в современной России (проблемы анализа и регулирования). Москва, 1999. 468 с. Текст: непосредственный.

10.Степанов Е. И. Конфликтология переходного периода: методологические, теоретические, технологические проблемы. Москва: Изд-во Института социологии РАН, 1996. 288 с. Текст: непосредственный. 
H. A. Жапова. Социальный конфликт с позиций синергетического подхода: социальнофилософский анализ

Статья поступила в редакиию 10.11.2021; одобрена после рецензирования 15.11.2021; принята к публикации 15.11.2021.

\title{
SOCIAL CONFLICT FROM THE PERSPECTIVE OF A SYNERGETIC APPROACH: SOCIAL AND PHILOSOPHICAL ANALYSIS
}

\author{
Natalya A. Zhapova \\ Cand. Sci. (Philos.), Senior Lecturer, \\ Dorzhi Banzarov Buryat State University \\ 24a Smolina St., Ulan-Ude 670000, Russia \\ tumann479@mail.ru
}

\begin{abstract}
The article is devoted to the social and philosophical analysis of the conflict from the perspective of a synergetic paradigm. We believe that in the study of social conflicts, the most effective approach is the theory of self-organization, which is implemented within the framework of system-synergetic approach. Due to its interdisciplinary nature and universality of laws and principles, a synergetic approach has great research potential in the study of social processes. It can be assumed that synergetics make it possible to introduce new knowledge into field of conflict knowledge and could become its ideological basis. Modern science is no longer guided by the ideals of immutability and linearity, therefore, in the study of conflicts it is also necessary to look for factors of self-organization, branches of strategies and bifurcations as a way out of crisis states. We come to the conclusion that the constancy of the very phenomenon of conflict in social space, the functional load of conflicts and the organic connection of conflicts with changes in social development should be taken into consideration.

Keywords: synergetics, systemic approach, social conflict, theory of self-organization, social system, society, conflict resolution, social transformation, globalization, social processes.
\end{abstract}

For citation

Zhapova N. A. Social Conflict from the Perspective of a Synergetic Approach: Social and Philosophical Analysis. Bulletin of Buryat State University. Philosophy. 2021; 4: 70-75.

The article was submitted 10.11.2021; approved after reviewing 15.11.2021; accepted for publication 15.11.2021. 